\title{
Foreign English Language Teachers' Local Pedagogy
}

\author{
Hamid Ali Khan Eusafzai ${ }^{1}$ \\ ${ }^{1}$ English Language Center Yanbu, Colleges \& Institutes Division, Royal Commission Yanbu, Saudi Arabia \\ Correspondence: Hamid Ali Khan Eusafzai, English Language Center Yanbu, Colleges \& Institutes Division, \\ Royal Commission Yanbu, Saudi Arabia. E-mail: haky2008@gmail.com
}

\author{
Received: February 2, 2015 Accepted: March 10, 2015 Online Published: April 23, 2015 \\ doi:10.5539/elt.v8n5p82 URL: http://dx.doi.org/10.5539/elt.v8n5p82
}

\begin{abstract}
ELT methods have been criticized for being limited and inadequate. Postmethod pedagogy has been offered as an alternate to these methods. The postmethod pedagogy emphasises localization of pedagogy and celebrates local culture, teachers and knowledge. Localizing pedagogy is easy for local teachers as knowledge and understanding of the local comes to them by instinct but may not be so for foreign teachers working in these local communities. However, it is also a fact that in the wake of globalization and internationalization, teachers are moving not only across geographical borders but also across cultural and social borders and to teach effectively, they need to localize their pedagogy. How do teachers localize their pedagogy in a foreign society? There is not much research on the phenomenon. The current qualitative research tries to bridge this gap. The research explored what aspects of the local are valued by expatriate teachers for particularizing their pedagogy; how this knowledge of the particular is translated into practice and to what extent it helps in socially and culturally empowering their students. The findings of the research are expected to help foreign teachers localize their pedagogy, and may also be helpful in designing orientation, integration and professional development courses for expatriate teachers.
\end{abstract}

Keywords: ELT methods, postmethod, local, teachers, pedagogy

\section{Introduction}

Any teaching situation entails learning and a concern to optimize learning. The concern often resulted in a quest for optimal teaching methods. Traditionally such a quest has been deemed the area of theorizers and academicians. Ironically, teachers who are the real actors in the classroom have been excluded from an active participation in the quest. They have been reduced to mere consumers of the teaching approaches and methods devised by academicians. The situation in the field of ELT has not been different. The field has been in the quest for optimizing language learning in the classrooms. The quest in the field of ELT resulted in producing a number of English language teaching methods. These methods have been devised in the idealized world of academicians educated and working in the Western societies. These academicians have little realization or understanding of the classroom realities of the contexts other than their own societies. As a result when these methods were implemented in the non-western contexts, they were found lacking in effectiveness. This led to a realization that for any teaching approach to be effective, it needs to be socially, culturally, and contextually situated and should stem from the very experience of the teachers teaching in that context. This means a local teaching approach, for local students devised by local teachers teaching in that local context. Based on this idea, a formal framework of English language teaching was presented by Kumaravadivelu $(2002,2005)$. The framework has been named as postmethod pedagogy.

Postmethod pedagogy presents principles and strategies for achieving context sensitivity and specificity in teaching. Since the initial proposal of the framework, in 1994, there has been little research on how teachers realize the principles of postmethod pedagogy in their teaching practices. Moreover, due to the mobility of language teachers across borders in the global world, foreign teachers find themselves teaching students in contexts and societies other than their own. To make their teaching effective and sensitive to the culture and needs of their local learners, teachers need to adopt certain principles and practices specific and sensitive to the local society and local learners. However, again there is a lack of sufficient research on foreign teachers' practice of localizing their pedagogy in a society foreign to these teachers. How do they achieve this localization? The current research report presents an effort finding an answer to this question. The research was done with the aim to explore what 'local exigencies' (Kumaravadivelu, 2006a) foreign TESOL teachers, working in higher 
education, consider effective in modifying their teaching practices to make them culturally and socially relevant and then how they achieve this relevance in their everyday practices. The research paradigm was critical and data was gathered through semi-structured interviews from a purposive sample.

The research report starts with a discussion of the limitations of ELT methods. It then briefly presents an introduction to the postmethod pedagogy and its principles. The introduction is followed by posing the research question. The research question is then followed by the methodology section leading to findings and discussion section. The research report culminates on a brief conclusion.

\section{ELT Methods: Boon or Bane}

An ELT method has been defined as a framework (Akbari, 2008a) or as an approach (Canagarajah, 2002) with a set of "procedures" (Kumaravadivelu, 1994) or "techniques" (Brown, 2002) for teachers to "replicate" (Prabhu, 1990) in their classroom with the intended goal of affecting language learning. The methods, thus defined, suggest the presence of guidelines and standard operational steps to be followed in the classroom. To the benefit of ELT teachers, it is suggestive of the presence of a repertoire of some "recipes" or prescriptions which a teacher can use in a classroom for "effective teaching" (Crandall, 2000, p. 37). ELT methods relieve teachers of the onus of being inventive by making available to them a toolbox of "predefined and pre-packaged" set of "instructional techniques" (Canagarajah, 2002, p. 142). The eventual benefit of this entire regime of techniqueprescriptivism is the qualitative enhancement of language learning (Prabhu, 1990). Due to these benefits, methods remained the "predominant paradigm" (Pennycook, 1989, p. 608) in the field of ELT and the field persistently invested in attempting to discover the best method.

However, there is a growing awareness that the field's infatuation with the methods has been futile, and the idea, that these methods can afford teachers with effective classroom procedures and techniques resulting in optimum learning, has been utopian in nature (Stern, 1985, as cited in Brown, 2002). The futility of the methods in relation to learning and teaching has also been vehemently substantiated by Kumaravadivelu (2006, p. 67):

the concept of method has only a limited and limiting impact on language learning and teaching, that method should no longer be considered a valuable or a viable construct......

The indictment of the methods being "too inadequate and limited" (Kumaravadivelu, 2005, p. 165), at the classroom level, is grounded in the claim that the language teaching and learning phenomenon as it happens in the classroom is too complex (Kumaravadivelu, 2002) as it involves an intricate interplay of various variations. The methods as a construct do not reflect this complexity (Pennycook, 1989) as they fail to take into consideration and explain the role of these variations. These variations include teachers and teachers' understanding of language teaching, learners and their wants and needs, the social and culture milieu inside the classroom, and the effect of external social and cultural environment on this milieu (Kumaravadivelu, 2002). These variations and their interplay in the language learning process differ from context to context. However, the methods "disregard the context of learning [and teaching]" (Tomlinson, 2005, p. 138), and assume a universality of problems and solutions (Kumaravadivelu, 2005). This, element of universality instead of being a strength, accounts for the limited and inadequate nature of methods as diversity of contexts means diversity of problems and a need for "context-specific solutions" (Kumaravadivelu, 2005, p. 165). The ELT methods, by ignoring the diversity of contextual variations, may be productive in one context but may yield inverse results in another context (Lochland, 2013), and thus the lament that " no single method is best for everyone, as there are important variations in the teaching context that influence what is best" (Prabhu, 1990, p. 162).

The indifference of the methods to the contextual variations has been attributed to the methods being conceptualized by academicians in the "realm of the ideas" (Akbari, 2008, p. 642) not derived from an analysis of the actual world of the language classroom (Pennycook, 1989). They are not based on "experience and experimentation" (Kumaravadivelu, 1994, p. 29) of the practicing teachers. This factor further strengthens the 'limited' and 'limiting' nature of the methods. The methods are limited because when applied in the language classrooms, they have been "found ... wanting [as] there is little concordance between what the concept purports to describe and what is actually happening in the classroom" (Pennycook, 1989, p. 589). These methods have also been limited because, being prescriptive, they deskill teachers by giving a recipe or toolkit only for "mechanical teaching" (Prabhu, 1990, p. 172) and "[conditioning] the form and function of classroom methodology restraining the practicing teacher from attempting anything radically different" (Kumaravadivelu, 2003, p. 546). Everyday classroom practices are diminished to mere standard procedures and rituals (Crandall, 2000) exerting pressures on teachers to perfect these procedures (Clarke, 2003) rather than developing capacity for context specific practical autonomous professional judgement and practice (Edge, 1996).

The ELT methods have also been excoriated for broader social, political, and educational reasons. Such 
disapproval results from the very nature of the methods as being prescriptive and context irrelevant. The context in this case is a larger global educational, social, cultural and political context. Prescriptivism, in this context, means a unidirectional transaction between a powerful giver and a disempowered receiver (Pennycook, 1989). The transaction, at the classroom level, is between academicians as theorists of the ELT methods and teachers as practitioners of the methods. However, at the level of a global educational world, it has been termed as a 'transplantation' of knowledge generated by the privileged Western theorists in the socio, cultural, educational and political milieu of the Western societies into the less privileged and undeveloped (as commonly projected) educational systems of the non-western societies. The two worlds, the developed and privileged western world and the unprivileged and underdeveloped non-western world, have been termed as 'centre' and 'periphery' (Pennycook, 1989). The transaction flows from the dominant centre to the dominated periphery and "the knowledge produced in the central academic institutions is legitimated through a series of political relationships that privilege it over other possible forms of knowledge" (Pennycook, 1989, p. 596). The use of political relationships for privileging and legitimizing knowledge reveals the 'political dimension' (Johnston, 1999) of Westernproduced knowledge dissemination. Knowledge has a political objective not only in dissemination but also in production because:

...knowledge is produced within a particular configuration of social, cultural, economic, political, and historical circumstances and therefore always both reflects and helps to (re)produce those conditions. Furthermore, since all claims to knowledge represent the interest of certain individuals or groups, we must always see knowledge as interested (Pennycook, 1989, p. 595).

The interested or political nature of knowledge suggests that knowledge or its form is not "an innocent, epistemological, neutral idea" (Pennycook, 1989, p. 597) but all forms of knowledge have "underlying values" (Edge, 1996, p. 17). These underlying values are the values of social relations based on power, authority, inequality and control.

The ELT methods, being a form of knowledge, also have political dimension and are not "value-free instruments" and their legitimization through certain political relations make them "cultural and political constructs with political-economic consequences" (Canagarajah, 2002, p. 135). The legitimization is achieved through an "ethnocentric discourse of power" (Holliday, 1997, p. 409) propagating a fallacy that the ELT methods devised in the West are "advanced" (Pennycook, 1989, p. 611), "universally relevant" (Phillipson, 1992, cited in Canagarajah, 2002), "the most effective, efficient and authoritative" (Canagarajah, 2002, p. 135) because these methods are coming from the "technologically and economically developed nations of the West" (Canagarajah, 2002, p. 135). Such a discourse helps to establish an unfair monopoly of the West creating a sort of "pedagogic imperialism" (McKay, 2003, p. 16). The Western models of English language teaching practices are projected as the best (Kumaravadivelu, 2013) and the models or practices of the undeveloped world are relegated as "deficit" (Ilieva \& Waterstone, 2013, p. 16). Though the reality is that the ELT methods projected and propagated as suitable for "global consumption" and "clientele" and "usable in all learning/teaching contexts" have proven inappropriate and inefficient in many teaching and learning contexts (Kumaravadivelu, 2003, p. 544).

The prescriptive nature of the ELT methods, and the political agenda embedded in this prescriptivism, makes these methods socially irrelevant (Kumaravadivelu, 2002). The prescriptivism ignores the fact that "classrooms operate within a cultural context which to a large extent determines not only what is to be learned, but also how it is to be learned" (Tudor, 1996, p. 210, cited in Tomlinson, 2005). The society outside the classroom affects the micro society in the classroom and no two societies are culturally, politically and historically the same (Kumaravadivelu, 2002). Such a premise entails diversity of the teaching learning situations and invalidates the need for a universal package suitable for all situations (Kumaravadivelu, 2003). It also entails the need for the forms of knowledge and the ELT methods or approaches which are rooted in the local. Such methods can best be devised by local teachers as they have a full grasp of the local context (McKay, 2003). The methods emerging therein will be 'context-sensitive' and 'community-specific' (Canagarajah, 2002). The limitations of the ELT methods and awareness to the need of localizing pedagogy led to the postmethod pedagogy.

\section{Postmethod Pedagogy}

The main strength of the postmethod pedagogy (PMP) is the recognition of the socially and politically situated nature of teaching. The PMP, in this way, is sensitive to the "local, individual, institutional, social and cultural context" in which a classroom operates (Kumaravadivelu, 2003, p. 544). The pedagogical paradigm emerges from the context rather than being prescribed and imposed from outside the context. This attribute makes the PMP responsive to the aspect of diversity which is inherent in any teaching learning situation. Such diversity can 
be a result of not only the peculiar social, cultural, and political factors which exist in the world outside a classroom but also internal factors such as the characteristics of a group of learners, their learning style and the societal and cultural influences which they bring to a language classroom.

The PMP has three basic principles: particularity, practicality and possibility (Kumaravadivelu, 2005). The principle of particularity requires teaching approaches to be holistically contextualized and localized (Kumaravadivelu, 2006b). The principle is appreciative of the specifics of "local linguistic, social, cultural and political" background (Kumaravadivelu, 2006b, p. 69). The objective is to situate teaching in the local and thus make it socially connected and relevant (Kumaravadivelu, 2002). Particularity can be considered as a pivotal principle of the PMP as contextual factors are at the heart of shaping teaching in the ELT classroom rather than the expertise of the teacher (Lochland, 2013).

The second principle, which of practicality, allows teachers to form their own context based teaching theories (Kumaravadivelu, 2005). Thus, through exercising the principle of practicality, a language teacher assumes the role of autonomous theorizer rather than a mere 'consumer' of externally prescribed theories (Kumaravadivelu, 2003). The principle of practicality is also linked to a teacher's sense of plausibility (Kumaravadivelu, 2005). A language teacher is an autonomous individual able to exercise professional autonomous judgment to make pedagogical decisions which are socially, culturally and politically relevant to the local context, and also has the capacity to judge the effectiveness of the practices resulting from these decisions.

The third principle of the PMP is the principle of possibility. As the principle of practicality is related to the empowerment and emancipation of teachers, the principle of possibility is related to the liberation and empowerment of the learners (Kumaravadivelu, 2005). The principle aims at "social transformation" (Kumaravadivelu, 2005) by developing learners' to "critically reflect on the social and historical conditions contributing to create the cultural forms and interested knowledge" (Kumaravadivelu, 2003, p. 544). Thus, in a way the principle attaches a political dimension to the PMP by assigning it the aim to develop an ideology or awareness towards an ideology among learners. Such a dimension implies the role of a teacher as a socio-politically engaged person aiming for social transformation (Johnston, 1999) rather than a mere conduit for the bare facts and knowledge of a target language rules or grammar. It also implies the role of learners as important social players with the ability to affect social transformation through critically reflecting on social, political and historical status quo of inequalities and not as mere passive recipients of grammar or vocabulary knowledge of a target language for a superficial aim of communicating in everyday mundane situations.

Acknowledging the shortcomings in the PMP (Bell, 2003; Akbari, 2008), the framework still offers great potential for improving language teaching. Even its critics, Bell (2003) and Akbari (2008), praise it for its liberating and invigorating capacity, and its realism and inclusiveness. Politically, the PMP has been celebrated for its potential to decolonize the ELT (Kumaravadivelu, 2003) by "de-linking" (McKay, 2003, p. 3) it from the prescriptivism of the theorizers of the centre and linking it to the local in the periphery (Block \& Cameron, 2002). The framework liberates and empowers the local and individual by challenging the monopoly of the centre (Arikan, 2006). The PMP created a space for the periphery teachers to "develop their own tradition of professionalism and expertise" (Canagarajah, 2002, p. 149). The pedagogy empowers local teachers by encouraging them to develop locally situated pedagogical strategies using their knowledge and expertise of the local learning needs of learners (Kumaravadivelu, 2003). The PMP, by empowering the local pedagogy, also empowers local knowledge (Canagarajah, 2002). The empowerment of the local knowledge and local pedagogy results in pedagogical approach and strategies which are "responsive to and responsible for local individual, institutional, social and cultural context in which learning and teaching take place" (Kumaravadivelu, 2003, p. 544).

\section{Research Question}

The PMP, in proclaiming local context, emphasizes local teacher and local knowledge. It emphasizes a pedagogy emerging from local cultural, political and social knowledge and exigencies (Kumaravadivelu, 2006b). Local teachers have a better grasp of such knowledge and exigencies as they are part of and immersed in the local context. The PMP, therefore, brings local teachers to the centre and privileges them for being better equipped to devise context specific pedagogical strategies. However, in the backdrop of globalization, internationalization of education, English having assumed the status of a lingua franca and the burgeoning demand for EFL teachers, the movement of ESL/EFL teachers across cultural, social and geographical borders is a growing reality. The movement is not only across international borders but even within ethnically, culturally and linguistically diverse nations, teachers may find themselves dealing with learners from different ethnic, cultural and linguistic backgrounds (Troudi, 2005). Either situation demands understanding the uniqueness of the teaching context and 
moulding teaching practices to make them more responsive to the local (Kumaravadivelu, 2003). This implies foreign teachers operating in a local context with a need to localize their pedagogy. The number of such situations and contexts in the world are myriad; however, studies investigating foreign teachers localizing their pedagogy in a culturally, politically, linguistically and socially different society are not many. The aim of the current study is to add to this limited research by investigation practices of the principles of the PMP by a group of foreign teachers in a society foreign to them. The single research question guiding this study is:

How do foreign TESOL teachers, working in higher education, realize the postmethod pedagogy in a local society?

\section{Methodology}

The current study is rooted in interpretive research paradigm. The underlying belief is that "one cannot understand the meaning that participants attribute to their actions, their thoughts, feelings, beliefs, values, and assumptive world." (Marshall \& Rossman, 1999, p. 57) without becoming a part of the meaning. As the aim was to understand the view point and experience of the research participants and the meanings attached by them to this experience (Scott \& Usher, 2011), therefore, the qualitative data collection technique of semi-structured interviews was opted. Interviews are considered "a uniquely sensitive and powerful; method for capturing the lived experiences and lived meanings of the subjects everyday world." (Kvale, 2007, p. 11). For this research data was collected through open-ended questions and probes drawn mainly from Kumaravadivelu's $(2002,2005)$ framework of postmethod pedagogy.

Data was analysed using the three stages protocol as described in Ary, Jacobs, Sorensen, and Walker (2013). In the first stage, the data was organized and read to gain familiarity with it; in the second stage data was coded and reduced and the third stage involved interpreting the data. The framework for coding involved a priori concepts derived from Kumaravadivelu's $(2002,2005)$ framework of postmethod pedagogy.

The research participants were selected purposively from amongst the colleagues of the researcher. A total number of 16 people participated in the research. All of them were English language teachers coming from diverse national and educational backgrounds. At the time of their participation in research, they were teaching in the English Language Centre (ELC) of a higher education institution on the Western coast of Saudi Arabia. Their teaching experience in a foreign context ranged from one to fifteen years.

To meet the ethical requirements, approval was sought from the manager of the ELC as the site and the teaching staff of the centre was involved in the data collection. The research participants were also informed of the purpose and area of the research. They were informed that their participation in research was of voluntary nature and they were not officially obliged to participate in the research. They were informed that they can withdraw from the research at any time. They were also assured of the confidentiality of the data and anonymity of their identity. Further, informed consent form was signed by all participants before the recording of the interviews.

Table 1. Demographics of the research participants

\begin{tabular}{llllll}
\hline $\begin{array}{l}\text { Participants } \\
\text { (pseudonyms) }\end{array}$ & Gender & Nationality & $\begin{array}{l}\text { Total Years of } \\
\text { Teaching }\end{array}$ & $\begin{array}{l}\text { Total Years of Teaching } \\
\text { in a Foreign Context }\end{array}$ & $\begin{array}{l}\text { Academic } \\
\text { Qualification }\end{array}$ \\
\hline Ayesha & female & Pakistani & 16 & 1 & PhD \\
Mustafa & female & Malaysian & 20 & 4 & MA \\
Adel & male & Turkish & 14 & 1 & MA, DELTA \\
Ahmed & male & Pakistani & 21 & 3 & MA, CELTA \\
David & male & Filipino & 15 & 3 & MA, PGCE \\
Adem & male & Turkish & 3 & 2 & MA, CELTA \\
Mark & male & Filipino & 13 & 4 & MA \\
Abdul & male & Nigerian & 13 & 3 & MA, CELTA \\
James & male & British & 11 & 6 & MA, PGCE \\
Stewart & male & Canadian & 15 & 9 & MA \\
Ali & male & Sudanese & 15 & 8 & MA \\
Hock & male & Malaysian & 25 & 10 & PhD \\
\hline
\end{tabular}




\begin{tabular}{llllll}
\hline Chris & male & British & 2 & 2 & MA,CELTA \\
Jane & female & American & 15 & 15 & EdD \\
Toledo & male & Filipino & 16 & 6 & EdD \\
Asim & male & Pakistani & 15 & 6 & MA, CELTA \\
\hline
\end{tabular}

\section{Findings and Discussion}

Data was analysed to see how foreign teachers realize the principles of the PMP in their daily pedagogical practices. There were two main objectives. The first objective was to know which aspects of the local they value for achieving "context-sensitivity and location-[specificity]" (Kumaravadivelu, 2006b) in their teaching. The second objective was to explore the ways these elements interact with the aspects of practicality and possibility of the PMP practices of this group of the research participants.

\subsection{Teachers' Consciousness of the Local}

Data was analysed to find those elements which teachers perceive shape their context specific teaching practices. These elements also form teachers' consciousness of the local. Such a consciousness helps teachers "understand their students and their [local] educational and language needs" (Troudi, 2005). Four elements emerged prominent. These elements are: the role of the English language in curriculum and society, learners' characteristics, role of teacher, and knowledge of the local culture. Following are the details of the specificities of these aspects of the groups' consciousness of the local. How these specificities interact with teachers' theorizing a local pedagogy, will be explained in the following section.

\subsubsection{Role of English}

A majority of teachers ( 9 participants) were of the opinion that the status of English makes their current context of teaching different from their own country. Saudi Arabia is essentially an EFL context. Teachers perceived that his difference shaped their pedagogical decisions and choices. David expressed his opinion regarding the status of English and its effect on teaching in the following words:

"I find teaching in these two contexts [participant's country and Saudi Arabia) as different. Primarily, the Philippines use English as a second language (ESL), so this difference influences my way of teaching."

The difference in teaching results as EFL and ESL situations require their own separate teaching strategies. Learners' knowledge of English and exposure to English in ESL contexts is different from learners' in EFL contexts. EFL learners' contact with English, in daily life, is limited both in terms of input and output. The situation requires teacher to create maximum opportunities of optimal contact with English within the walls of the classroom. Therefore, EFL teaching requires strategies which increase the input and output opportunities for learners within the four walls of the classroom. Ahmed expressed his cognizance of the situation in the following words:

"In my country English is ESL..... so there is higher level of exposure and comprehension in English. In KSA, Arabic is official language and English teaching in schools is not very effective. The students who come to preparatory year .... are generally weak in English skills."

Thus, due the unique learning needs existing in an EFL context, teachers' perception of the status of English as an element of influence on their pedagogy is valid.

\subsubsection{Learners' Characteristics}

The second dominant factor influencing the pedagogical approach of the teachers was learners' characteristics. Data revealed unanimity across the participants on this factor though there was a diversity of opinion on individual characteristics. Lackadaisical and causal attitude (mentioned by 4 participants), lack of motivation (mentioned by 5 participants) and lack of autonomy (mentioned by 3 participants) emerged as main individual characteristics which shape pedagogical decisions of the teachers:

"Generally speaking, the students here have very laid back attitude towards learning. A lot of times students feel reluctant to fully participate in the class. They do not want to do homework even. They seem to have the need to spoon-fed learning style" (James)

Participant 8 mentioned lack of motivation as a difficulty to be overcome in the classroom:

"Some of the major difficulties include demotivation on the side of the students, which is slowing down learning. Demotivation and sometimes resistance to cooperation in group and peer work." (Abdul) 
Teachers perceive the main learners' characteristics of casualness, demotivation and lack of autonomy situation-specific and unique to their current context of teaching in Saudi Arabia.

\subsubsection{Teachers' Role Expectation}

Knowledge of teachers' role expectation (mentioned by 8 participants) is another constituent of this group's consciousness of the local which is valued for enabling teachers to contextualize and localize their pedagogy. These expectations are unique to the context of their teaching in the KSA and different from that of teachers' own society. The context-specific role expectations are perceived to make teachers adjust teaching to make it more responsive to the local context. The opinion expressed below is representative of the general opinion of the group about teacher's role perception:

"Students in this context prefer the teacher with the traditional authority, or figure of being a transmitter of knowledge. Their perception of what a good teacher is, that is, a good teacher transmits knowledge through spoon feeding." (Adem)

\subsubsection{Knowledge of Local Culture}

Teachers expressed an awareness of differences between their own culture and the culture of the students in their current context of EFL pedagogy. They considered the cultural differences as a factor requiring them to adjust their teaching approach to make it more relevant to their learners.

"The challenge that I face is to ensure that lessons and material remain culturally appropriate to my Saudi students. I know that I cannot use any material the way I can liberally use in Philippines. ...adjustments in teaching were more based on knowing the country's social, cultural and political norms." (David)

Regarding the nature of difference, the main difference was cited (by 7 participants) to be the conservative nature of the society and resultantly the students in the classroom:

"Conservative, my students are conservative and they want to stick to it inside the classroom." (Asim)

An important consideration was to find out how these foreign teachers acquire this local social, cultural and political knowledge. Such knowledge is innate to local teachers but foreign teachers have to make conscious effort to become familiar with local culture. The participants informed that they acquire knowledge of the local culture through colleagues, and students:

"I acquire knowledge of the local culture, social values and political trends that may be relevant to my teaching practice by reading relevant literature in and about Saudi Arabia, by mingling with the local colleagues, by talking with the students." (Mark)

\subsection{Theorizing and Practicality}

Practicality is "to understand and assess [local] information, consider and evaluate alternatives and then choose the best available alternatives" (Kumaravadivelu, 2002, p. 35). The data analysis revealed that the constituents of the particular led to the teachers' adjusting their teaching approach and adopting alternative strategies to make their teaching context-specific and learners-sensitive.

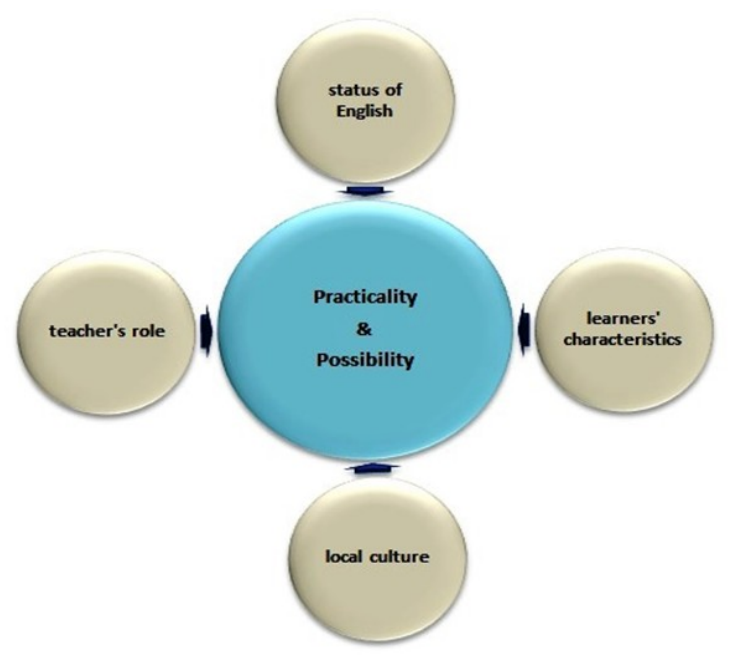

Figure 1. Elements of the local affecting the aspects of practicality and possibility 
"Teaching for me is most effective if it is carefully designed within the learners' context. Learning goals, contents, methods and strategies, learning resources, and evaluative techniques must reflect the local colour of culture of the learners so they can connect themselves within the leaning context." (Mark)

To bring in the 'local colour', the teachers adjusted their teaching approach. Knowing the limited capacity of the learners, their low motivation and lack of autonomy, the teachers make behavioural adjustments in their teaching approach.

"The context has made me revise my teaching methods and techniques; [context] has made me more patient and less ambitious in expecting results and I have become a little more systematic. I am more flexible; my lesson plans are tentative and ready to change depending on the situational needs and learners' mood". (Ayesha)

Though flexibility can be helpful in handling unforeseeable classroom situations and learning needs (Kumaravadivelu, 2002), but the teachers consider flexibility important for keeping learners motivated and enhancing their achievement.

"I'm flexible as it helps my students. If I'm ready to change for them they work well." (David)

The use of the principle of flexibility is evident mainly in the area of assessment and setting learning objectives. The use of flexible assessment practices help in setting easy and achievable targets for students and keeping them motivated by giving them a sense of achievement.

"To keep them motivated, I give them short term and easily achievable targets and slowly moving them to the challenging level. I ask them how they want to be assessed." (Toledo)

The use of flexible assessment techniques indicate that teachers are not slaves (Shohamy, 2004) to assessment, rather they use it as a tool to meet certain learning needs of their local students. The use of flexible assessment is also linked to giving students opportunities to "make personal decisions about a course of action" related to their "own learning" and provision of such opportunities is linked to "social, economic and cultural rights" as the learners can "negotiate practices different from those that are proposed" (Leach, Neutze, \& Zepke, 2001, p. 294). Therefore, negotiating assessment strategies with learners not only contributes to developing their autonomy but also empowers them as learners. In addition to using flexible assessment to the location-specific advantage of the learners, the teachers are also flexible in setting learning objectives for their lessons. Flexibility in this case is linked to teachers using it to modify the syllabus and the lessons to make it appropriate to the learning needs of their students.

"Start with an objective. Adapt and adapt as the class goes along. Check for achievement and expected results as the class goes by and adapt again." (Hock)

The teachers also made an attitudinal adjustment in terms of cultural sensitivity and empathy with the local students.

"You have to be extra careful about religious and cultural issues here. The students can easily get offended as they expect you to sympathise with their interpretation of issues." (Ayesha)

These teachers link empathy and sensitivity to better learning.

"I obtain better results when I am flexible and compassionate with the students.... I believe that students learn better because of the empathy I display in my interaction with them." (Ali)

Cultural sensitivity results in the teachers using material linked to the local culture rather than material with references to the target language culture.

"I incorporate texts and materials about the Arabic culture, rather than that of the target language culture. Learning is difficult if the concept is alien to the students. So rather than teaching something through a text about Abraham Lincoln, I do it through a text about Ghazi Algosaibi." (Adem)

Adopting material rooted in local culture not only achieves cultural and social relevance but also promotes learning; for being familiar such material effectively activates students' schemata and keeps them motivated and increases classroom interaction.

"Developing the context for most activities around the local culture makes it palatable for my students. They like to talk about their familiar context. They have a worldview which is different from other cultures and I exploit the element of that worldview." (Ahmed)

An added advantage of using local culture and material based on local culture is the learners' social empowerment: "local culture has the added value of enabling learners to think about the different aspects of the culture in which they live and find ways to bring about changes in the society where change is needed" (Akbari, 
2008b, p. 279). As social empowerment of learners is a basic principle of the possibility parameter of the PMP, thus it can be concluded that the use of local culture by these teachers is linked to the possibility aspect of their postmethod pedagogy as well. Thus, the aim of cultural sensitivity and empathy is not only to support the language learning of the local students but also to empower them by recognizing their individual, social, and cultural identity (Akbari, 2008b).

Linked to the identity and empowerment is the recognition of a role of L1 of the local learners as "an individual's L1 is part of his or her identity" (Akbari, 2008b, p. 280). The group of teachers reported the judicious use of L1 in the classroom. Abdul reported using L1 in class to support learning.

"Monolingual factor is linked to culture and society. It affects my teaching in the sense that sometimes I resort to using L1 strategically to aid learning."

Care appears to be another aspect of the teachers' theorizing of a local pedagogy. Care symbolizes "a solidarity with and a valuing of students, including students' lives, development, human dignity, culture, and future success" (Taylor \& Sobel, 2011, p. 98). Care in this sense is linked to the recognition of the learner as a valuable individual and in this way is linked to the empowerment of the individual leaner. The group of teachers participating in the research believed that by displaying care, they can build better rapport with students. Such rapport can be motivational and results in improved learning. Hock echoed this in the following words:

"The students do not respond directly. You have to gain their trust by showing them that you care. They are not just students; they are first and foremost human beings that have their own ups and downs. Listen and listen again, ... if you spend time listening to them, they are more likely to listen to you and take your advice on how to improve."

Toledo linked rapport to motivation in these representative words:

"To improve motivation, the first thing for me is the classroom environment. I try to establish good rapport with my students. I try to keep a friendly and less stressful environment in my class..."

Elements of care and rapport results in adopting classroom practice of negotiating students' choice with them in terms of pair work, group work or teacher talk. Such negotiation can be helpful in reducing "perceptual mismatch" (Kumaravadivelu, 2002, p. 39) between learners and teachers.

"I do ask if they prefer to do an activity in groups or with a partner or individually. I lecture them if they want me to teach and make my classes more teacher-centred." (Mustafa)

Teachers' "pedagogical thoughtfulness" (Kumaravadivelu, 2005, p. 173) is at the heart of the teachers' willingness to negotiate students' choice with them. It also emanates from the teachers' theorizing that rapport with students can lead to the effectiveness of their pedagogy in a foreign context.

"If we are willing to listen, we are bound to find out what makes them tick and participate in beneficial class activities that actually help them to learn." (Hock)

Thus, the emerging theme is that the teachers use care and its aspect of negotiation to achieve "connectedness" (O'Connor, 2008, p. 118) with their local students with an aim to nurture their learning by keeping them motivated through interpersonal rapport and by negotiating classroom interaction choices with the students. Care and the aspects of rapport building and negotiation help in promoting dialogue and collaboration inside the classroom (Auerbach, 2000). They create a participatory environment where the element of teachers' imposition of one-sided decisions is reduced and learners have greater opportunities of "self-actualization" (Auerbach, 2000, p. 145).

The representative extracts from the participants' interviews quoted in this section, afford a glimpse into "context-sensitive pedagogic knowledge" (Kumaravadivelu, 2005, p. 173) of the teachers. The main constituents of the knowledge are flexibility, cultural sensitivity and care. The uniting element of the three constituents is to increase the learning opportunities (LO) for the students. Teachers attach importance to those principles and strategies which may result in enhanced learning and better achievement of the students. 


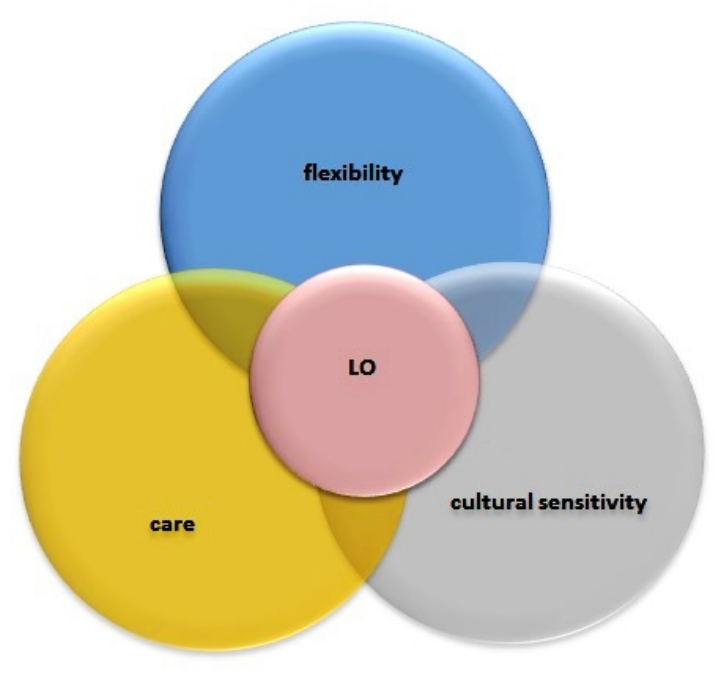

Figure 2. Constituents of foreign teachers' local pedagogical knowledge

\subsection{The Principle of Possibility}

The principle of possibility expects teachers to play a socially engaging role and meet the "social needs" of their learners (Kumaravadivelu, 2005). The findings revealed that the teachers, despite their being foreign, are fully aware of the social and transformative aspect of their role.

"I consider education to be one of those rare professions in which one can contribute to the good of mankind through the improvement of a single individual at a time." (Hock)

The individual improvement has a social purpose.

"I let the students feel that they are valuable members of the society and that they study for the main purpose of reconstructing or improving the society where they belong." (Mark)

To achieve this social objective, the strategies of awareness raising and experience comparison are adopted.

"I try to instil civic-mindedness in my students and remind them that they are part of a whole. I also try to bring in my own world experience so they can compare with their own society. Often times, I give them situations or activities where they can apply higher levels of thinking into the situation." (Mustafa)

Thus, foreignness is not considered an obstacle to the teachers' role as an agent of social change. They are ready to play this role by cultivating awareness among students about students' role in their society and then providing them opportunities to reflect on how the students can be active social reform agents. Thus, the teachers do not limit their role to the walls of the classroom and their pedagogy to the teaching of language system; rather they contribute to the students' "educational advancement" as well as to their "personal transformation" (Kumaravadivelu, 2002, p. 14). The teachers' commitment to their role as social reformers is in contrast to the limitations mentioned by Akbari (2008). One of the limitations mentioned by him is foreign teachers' avoidance to discuss culturally sensitive topic in their foreign classrooms. However, in the data analysis for this research we find evidence of teachers empowering their students' social being through various appropriate strategies.

"Specific strategies are group discussion or informal debates about social or economic problems afflicting the Kingdom, for example, women's rights, employment, business etc. Problem-based learning through research or WebQuestsare appropriate strategies. The presence of social evils or problems in society affects the way we teach our students. Hence, teachers must be aware and sensitive of these issues and must be reflected in the EFL curriculum." (Mark)

\section{Conclusion}

The aim of the current research was to explore how a group of foreign teachers' have localized their pedagogy to make it appropriate and suitable for their local learners. Kumaravadivelu $(2002,2005)$ framework of postmethod pedagogy was used for the study. The effort was successful in capturing "the reality of the lives" (Akbari, 2008, p. 641) of foreign teachers in a foreign society in terms of their practice of PMP. We discovered that teachers 
adopted certain theoretical principles to make their teaching context sensitive and learners specific. The main principles were the principles of flexibility, cultural sensitivity and care. The core and uniting belief of all these three principles is that they increase the learning opportunities for the learners. We also discovered that learners' empowerment is also one of the main aim of the teachers' pedagogical decisions.

The finding of this study can be helpful in organizing orientation and professional development programs for foreign teachers joining a foreign context like the one in which this study was carried out. Such programs can help them teach effectively in their foreign context by adopting learners' specific, culturally sensitive and flexible pedagogy to the benefit of the learning of their students.

The study has certain limitation. Female teachers are under-represented in the study. Only 3 female teachers were able to participate in the study. This resulted from the gender segregation that is the norm of Saudi education system. Apart from that the study mainly depended on teachers' reporting of their practices through semi-structured interviews. This provided only a partial picture of teachers' practice of the PMP. An ethnographic study involving observation of teachers' practices inside the classroom spread over an extended period of time can help capture a complete picture of the teachers' theorizing and resulting practice of the principles of postmethod pedagogy.

To conclude, the study despite its limitations contributed to widening the horizon of postmethod pedagogy research. Research in the practicalities of the postmethod pedagogy is scarce and the study is an addition to this research. The study may help inform certain policy and professional development decisions and may also help and enlighten those practitioners who are aiming to localize their pedagogy.

\section{References}

Akbari, R. (2008a). Postmethod discourse and practice. TESOL Quarterly, 42(4), 641-652.

Akbari, R. (2008b). Transforming lives: Introducing critical pedagogy into ELT classroom. ELT Journal, 62(3), 276-283. http://dx.doi.org/10.1093/elt/ccn025

Arikan, A. (2006). Postmethod Condition and Its Implications for English Language Teacher Education. Online Submission, 2(1).

Ary, D., Jacobs, L., Sorensen, C., \& Walker, D. (2013). Introduction to research in education. Cengage Learning.

Auerbach, E. R. (2000). Creating participatory learning communities: Paradoxes and possibilities. In J. Hall, \& W. Eggington (Eds.), The sociopolitics of English language teaching (pp. 143-164). Clevedon: Multilingual Matters.

Bell, D. (2003). Method and postmethod: Are they really so incompatible? TESOL Quarterly, 37(2), 325-336. http://dx.doi.org/10.2307/3588507

Block, D., \& Cameron, D. (Eds.). (2002). Globalization and language teaching. Psychology Press.

Brown, H. (2002). English language teaching in the "post-method" era: Toward better diagnosis, treatment, and assessment. In Methodology in language teaching: An anthology of current practices (pp. 9-18). Cambridge Univ Press. http://dx.doi.org/10.1017/CBO9780511667190.003

Canagarajah, A. (2002). Globalization, methods, and practice in periphery classrooms. In D. Block, \& D. Cameron (Eds.), Globalization and language teaching (pp. 134-150).

Clarke, M. (2003). A place to stand: Essays for educators in troubled times. University of Michigan Press.

Crandall, J. (2000). Language teacher education. Annual Review of Applied Linguistics, 20, 34-55. http://dx.doi.org/10.1017/S0267190500200032

Edge, J. (1996). Cross-cultural paradoxes in a profession of values. Tesol Quarterly, 30(1), 9-30. http://dx.doi.org/10.2307/3587605

Holliday, A. (1997). The politics of participation in international English language education. System, 25(3), 409-423. http://dx.doi.org/10.1016/S0346-251X(97)00032-8

Ilieva, R., \& Waterstone, B. (2013). Curriculum Discourses Within a TESOL Program for International Students: Affording Possibilities for Academic and Professional Identities. TCI (Transnational Curriculum Inquiry), 10(1), 16-37.

Johnston, B. (1999). Putting critical pedagogy in its place: A personal account. TESOL Quarterly, 33(3), 557-565. http://dx.doi.org/10.2307/3587680 
Kumaravadivelu, B. (1994). The postmethod condition: (E) merging strategies for second/foreign language teaching. Tesol Quarterly, 28(1), 27-48. http://dx.doi.org/10.2307/3587197

Kumaravadivelu, B. (2002). Beyond methods: Macrostrategies for language teaching. Yale University Press.

Kumaravadivelu, B. (2003). A postmethod perspective on English language teaching. World Englishes, 22(4), 539-550. http://dx.doi.org/10.1111/j.1467-971X.2003.00317.x

Kumaravadivelu, B. (2005). Understanding language teaching: From method to postmethod (Ed.). Routledge.

Kumaravadivelu, B. (2006a). Dangerous liaison: Globalization, empire and TESOL. In J. Edge (Ed.), (Re)Locating TESOL in an Age of Empire (pp. 1-25). London: Palgrave/Macmillan. Retrieved from http://bkumaravadivelu.com/articles in pdfs/2006b Kumaravadivelu Dangerous Liaison.pdf

Kumaravadivelu, B. (2006b). TESOL methods: Changing tracks, challenging trends. Tesol Quarterly, 40(1), 59-81. http://dx.doi.org/10.2307/40264511

Kumaravadivelu, B. (2013). Rethinking Global Perspectives and Local Initiatives in Language Teaching. In S. Said, \& L. Zhang (Eds.), ...Teachers and Teaching: Global Perspectives... (pp. 317-323). Routledge.

Kvale, S. (2007). Doing interviews. London: Sage.

Leach, L., Neutze, G., \& Zepke, N. (2001). Assessment and empowerment: Some critical questions. Assessment \& Evaluation in Higher Education, 26(4), 293-305. http://dx.doi.org/10.1080/02602930120063457

Lochland, P. (2013). Moving beyond communicative language teaching: A situated pedagogy for Japanese EFL classrooms. TESOL Journal, 4(2), 261-273. http://dx.doi.org/10.1002/tesj.57

Marshall, C., \& Rossman, G. (1999). Designing qualitative research (3rd ed.). London: Sage Publications.

McKay, S. (2003). Towards an appropriate EIL pedagogy: Re-examining common ELT assumptions. International Journal of Applied Linguistics, 13(1), 1-22. http://dx.doi.org/10.1111/1473-4192.00035

O'Connor, K. (2008). "You choose to care": Teachers, emotions and professional identity. Teaching and Teacher Education, 24, 117-126. http://dx.doi.org/10.1016/j.tate.2006.11.008

Pennycook, A. (1989). The concept of method, interested knowledge, and the politics of language teaching. TESOL Quarterly, 23(4), 589-618. http://dx.doi.org/10.2307/3587534

Prabhu, N. (1990). There is no best method-why? Tesol Quarterly, 24(2), 161-176. http://dx.doi.org/10.2307/3586897

Scott, D., \& Usher, R. (2011). Researching education. NY: Continuum international.

Shohamy, E. (2004). The power of tests over teachers: The power of teachers over tests. In D. Tedick (Ed.), Second language teacher education: International perspective (pp. 101-111). Mahwah, NJ: Erlbraum.

Taylor, S., \& Sobel, D. (2011). Culturally responsive pedagogy: Teaching like our students' lives matter. Bingley, UK: Emerald Group Publishing Limited. http://dx.doi.org/10.1163/9781780520315

Tomlinson, B. (2005). English as a foreign language: Matching procedures to the context of learning. In E. Hinkel (Ed.), Handbook of research in second language teaching and learning (pp. 137-154). Routledge.

Troudi, S. (2005). Critical content and cultural knowledge for TESOL teachers. Teacher Development, 9(1), 115-129. http://dx.doi.org/10.1080/13664530500200233

\section{Copyrights}

Copyright for this article is retained by the author(s), with first publication rights granted to the journal.

This is an open-access article distributed under the terms and conditions of the Creative Commons Attribution license (http://creativecommons.org/licenses/by/3.0/). 